\title{
CÓDIGO FLORESTAL BRASILEIRO, AGRICULTURA FAMILIAR E ASSENTAMENTOS RURAIS
}

\author{
BRAZIL'S FOREST CODE, FAMILY FARMING AND RURAL SETTLEMENTS
}

\author{
Virgínia Totti Guimarães ${ }^{36}$ \\ Juliana Chermont Pessoa Lopes ${ }^{37}$ \\ Paula Máximo de Barros Pinto ${ }^{38}$
}

Artigo recebido em: 28/11/2018.

Artigo aprovado em: 17/12/2018.

\begin{abstract}
Resumo: O presente trabalho visa analisar as normas do Código Florestal de 2012 aplicáveis aos agricultores familiares e, ainda, aos assentamentos rurais. A metodologia baseia-se em pesquisa e análise crítica da bibliografia, bem como levantamento de dados específicos relativos ao Cadastro Ambiental Rural. As peculiaridades do tratamento destinado aos assentamentos rurais no processo de inscrição no Cadastro Ambiental Rural (CAR) são analisadas, objetivando-se apresentar questionamentos sobre os direitos e garantias dos assentados decorrentes desse cadastramento. $\mathrm{O}$ trabalho traz reflexões acerca das Cotas de Reserva Ambiental originárias de assentamentos rurais. Verificou-se que, no que se refere ao CAR, a maioria das regras específicas sobre assentamentos rurais direciona-se à simplificação dos procedimentos, mas não houve previsão sobre a necessária participação dos assentados na geração das informações a serem incluídas no Cadastro, bem como a garantia de amplo acesso aos estudos e dados produzidos no âmbito do INCRA. No que se refere aos pagamentos por serviços ambientais, além dos debates relativos a mercantilização da natureza, não há sequer menção sobre as cotas originadas de excedentes de vegetação nativa em assentamentos rurais, o que gera uma série de questionamentos a respeito dos direitos garantidos nos procedimentos estabelecidos pelo Código Florestal.
\end{abstract}

Palavras-chave: Código Florestal; assentamentos rurais; Cadastro Ambiental Rural (CAR)

\begin{abstract}
This work aims to analyze the rules of the Forest Code of 2012 applicable to family farmers, and especially those specific rules applied to rural settlements. The methodology is based on research and critical analysis of the bibliography, as well as the collection of specific data related to the Environmental Registry of Rural Properties. The peculiarities of the treatment to the rural settlements durying the process of registration in the Environmental Registry of Rural Properties (CAR) were analyzed aiming to present questions about the rights and guarantees of the settlers. The work brings reflections about the Environmental Reserve Quotas created from forests inside rural settlements. It was verified that, regarding to the CAR, most of the specific rules about rural settlements in the Forest Code are directed to the simplification of the procedures, but there was no prediction about the necessary participation of the settlers in the generation of the information to be included in the registry, as well as the guarantee of others access to studies and data produced within INCRA. In addition, as far as payments for environmental services are concerned, besides the discussion about the natures mercalization, there is no mention of the generation of

\footnotetext{
${ }^{36}$ Doutora em Direito pela Pontifícia Universidade Católica do Rio de Janeiro. Professora da Pontifícia Universidade Católica do Rio de Janeiro.

${ }^{37}$ Graduada em Direito pela Pontifícia Universidade Católica do Rio de Janeiro. Estudante de Especialização em Políticas Públicas e Planejamento Urbano (IPPUR/UFRJ)

${ }^{38}$ Graduanda em Direito pela Pontifícia Universidade Católica do Rio de Janeiro.
} 
quotas originating from native forest inside rural settlements, which translates into a series of questions regarding the implementation of the Forest Code.

Keywords: Forest Code; rural settlements; Environmental Registry of Rural Properties (CAR).

\section{INTRODUÇÃO}

O Código Florestal de 2012 (Lei 12.651/2012) é resultado de um processo legislativo polêmico, em que se pode dizer que prevaleceram os interesses de determinado setor agrícola, atualmente representado pela Bancada Ruralista no Congresso Nacional. ${ }^{39}$ Durante suas discussões, muito se argumentou sobre a necessidade de alteração das normas florestais para beneficiar a agricultura familiar, quando na verdade se tratava de interesses de grandes proprietários.

Três são os pilares do Código Florestal aprovado em 2012. O primeiro é a diminuição das regras de proteção ambiental, por meio da alteração de critérios técnicos para definição de áreas de preservação permanente (APP’s), do estabelecimento de exceções ao regime geral de proteção destas áreas, da diferenciação jurídica entre apicuns e manguezais, dentre outros. O segundo pilar do Código Florestal de 2012 refere-se as ilegalidades, e é a regularização de atividades que ocorriam em dissonância à legislação em vigor, mediante a criação da área rural consolidada, bem como pela anistia de multas e crimes relativos ao revogado Código (Lei 4.771/1965). O terceiro pilar é a instituição de um mercado de pagamento por serviços ambientais no Brasil.

O presente artigo tem como objetivo analisar as normas do Código Florestal específicas sobre agricultura familiar e assentamentos rurais, como forma visibilizar o debate sobre os direitos destes sujeitos e discutir o processo político que os tem preterido em detrimento de outros interesses. Tem-se como pressupostos, de um lado, a extrema importância da agricultura familiar, com a necessária discussão sobre políticas públicas que a viabilizem e desenvolvam, e, de outro, o acirramento de uma agenda política de benefício ao agronegócio e agricultura extensiva.

A importância da agricultura familiar possui, ao menos, três dimensões que merecem ser destacadas, desde já. A primeira refere-se à identidade de ser agricultor ou camponês, o que inclui o direito a permanecer como tal, por meio de um estilo de vida próprio, vinculado à prática de atividades no campo. Não se pode negar tal direito a esse grupo social, fundamental para a constituição de identidades no Brasil. A segunda dimensão refere-se ao modo de distribuição no território brasileiro, muito extenso, e que não pode prescindir de ocupação humana em áreas rurais ou destinadas a atividades agropastoris. Outro fator está relacionado à relevância da agricultura familiar para produção de alimentos e do modo como isso ocorre. Como exemplo, destaca-se que, segundo informações do Governo Federal, apenas 30\% dos

\footnotetext{
${ }^{39}$ Entende-se como Bancada Ruralista a Frente Parlamentar da Agropecuária, instituída a cada mandato legislativo do Congresso Nacional.
} 
alimentos produzidos pela agricultura industrial chegam aos pratos da população mundial enquanto $70 \%$ são produzidos pela agricultura familiar. ${ }^{40}$ Além disso, a agricultura familiar e os assentamentos de reforma agrária, em especial os do Movimento dos Trabalhadores Sem Terra (MST), produziram cerca de 27 mil toneladas de arroz orgânico na safra $2017 .^{41}$

Em relação à agenda política em curso atualmente, volta-se ao fortalecimento da agropecuária e da agricultura extensiva que tem recebido destaque no Congresso Nacional. Pode-se citar, como exemplo recente, a discussão do "Pacote do Veneno", ${ }^{42}$ projeto de lei cujo objetivo é facilitar a aprovação e liberação de agrotóxicos no Brasil, que, além de apresentarem risco à saúde da população, aos trabalhadores rurais e ao meio ambiente, demonstra o modelo de agricultura que se pretende ampliar no país.

Especificamente acerca da legislação florestal, deve-se notar que um dos instrumentos criados pelo Código Florestal é o Cadastro Ambiental Rural (CAR), que se configura como elemento central para o desenvolvimento das políticas públicas florestais, sendo um registro público nacional, com as informações ambientais relativas às propriedades e posses rurais. Objetiva-se assim, a analisar as regras específicas desse cadastro aos assentamentos rurais, como forma de identificar e estudar os direito e garantias dos assentados em questão, apresentando-se, anteriormente, o CAR e suas principais características. Por fim, pretende-se introduzir algumas discussões acerca das Cotas de Reserva Ambiental (CRA`s), igualmente previstas no Código, originárias de assentamentos rurais.

\section{DISCUSSÕES ATUAIS SOBRE OS DIREITOS DOS AGRICULTORES FAMILIARES E ASSENTADOS DA REFORMA AGRÁRIA}

A agricultura familiar está atrelada a questões que envolvem o acesso à terra e a reforma agrária. Apesar de ser uma atividade de importância ímpar ao abastecimento de alimentos e segurança alimentar, ${ }^{43}$

40 Disponível em <http://www.mda.gov.br/sitemda/noticias/brasil-70-dos-alimentos-que-v\%C3\%A3o-\%C3\%A0-mesa-dosbrasileiros-s\%C3\%A3o-da-agricultura-familiar>. Acesso em: 25 nov.2018.

${ }^{41}$ Disponível em: <http://www.ihu.unisinos.br/78-noticias/578344-mst-colheu-27-mil-toneladas-de-arroz-sem-veneno\# > Acesso em: 28 nov. 2018.

42 Apelidado de "Pacote de Veneno" por sua proposta de flexibilização das normas que regulamentam o uso de agrotóxicos no Brasil, o Projeto de Lei de autoria do Senador Blairo Maggi, com número na Câmara dos Deputados de PL 6.299/2002, pretende alterar a Lei $\mathrm{n}^{\circ} 7802$, de 11 de julho de 1999, que "dispõe sobre a pesquisa, a experimentação, a produção, a embalagem e rotulagem, o transporte, o armazenamento, a comercialização, a propaganda comercial, a utilização, a importação, o destino, a classificação, o controle, a inspeção e a fiscalização de agrotóxicos, seus componentes e afins, e dá outras providências." Atualmente foi requerida a realização de Audiência Pública para debater as propostas relativas à regulamentação destes. A tramitação pode ser acompanhada no site da Câmara dos Deputados. Disponível em: http://www.camara.leg.br/buscaProposicoesWeb/resultadoPesquisa?numero=\&ano=\&autor=\&inteiroTeor=PL+6299/2002\&emtra mitacao=Todas\&tipoproposicao=\%5B\%5D\&data=28/11/2018\&page=false Acesso em 28 jun. 2018

43 Entendemos como segurança alimentar: "direito de todos ao acesso regular e permanente a alimentos de qualidade, em quantidade suficiente, sem comprometer o acesso a outras necessidades essenciais, tendo como base práticas alimentares promotoras da saúde, que respeitem a diversidade cultural e que sejam ambiental, cultural, econômica e socialmente sustentáveis." MACHADO, Renato Luiz Abreu. Segurança Alimentar, Nutricional e Soberania Alimentar. Disponível em: <http://www4.planalto.gov.br/consea/acesso-a-informacao/institucional/conceitos>. Acesso em: 25 nov.2018. 
dentre outros fatores, a agricultura familiar esbarra em dificuldades inerentes à histórica concentração de terras existente no Brasil ${ }^{44}$ e ao fortalecimento, nos últimos anos, da agricultura extensiva, sobretudo após a revolução verde. Ilustra bem estas dificuldades, o fato de que, mesmo consagrada na Constituição Federal de 1988, a função social da propriedade ${ }^{45}$ ainda gera, após 30 anos, inúmeros debates nos campos jurídico e político, com muitas resistências para a imposição de limites ao exercício do direito de propriedade e sua conformação a uma função social e ambiental.

Nos últimos anos, percebe-se uma articulação em torno de temas referentes ao acesso à terra, tanto em relação ao desmonte de políticas de reforma agrária, quanto em relação à possibilidade de concentração de grandes áreas rurais. Entende-se que a reforma agrária é a espinha dorsal para discussões que envolvam direitos de agricultoras(es), sobretudo, os que se relacionem com direitos socioambientais e a participação desses na gestão dos ativos florestais e de biodiversidade no Brasil.

O desmonte da política de reforma agrária pode ser percebido em diversas dimensões, como com a redução gradual da criação de novos assentamentos e a dificuldade de acesso a créditos que permitem a consolidação e reprodução da vida das famílias. Nesse contexto, insere-se a Lei federal 13.465/17, resultado a conversão da Medida Provisória 759/16, que dispõe sobre a regularização fundiária rural e urbana, sobre a liquidação de créditos concedidos aos assentados da reforma agrária e sobre a regularização fundiária no âmbito da Amazônia Legal, dentre outros assuntos. A Lei evidencia a prevalência de políticas públicas voltadas à produção de títulos individuais de propriedade ou posse em detrimento da reforma agrária, que somente é possível por meio do encadeamento de ações públicas voltadas para criação de assentamentos rurais, com políticas setoriais que levem à sua estruturação e posterior emancipação, bem como a condições que possibilitem a permanência dos assentados na produção rural. Neste sentido, destacam-se três questões centrais da Lei 13.465/2017: (i) a seleção de famílias beneficiárias do Programa Nacional de Reforma Agrária - PNRA; (ii) a consolidação e emancipação dos assentamentos; e (iii) a titulação provisória e definitiva dos parcelamentos concedidos.

O Decreto 9.311/18 ${ }^{46}$ estabelece que a seleção das famílias beneficiárias ocorrerá mediante edital público municipal para cada projeto de assentamento, através dos quais as famílias, individualmente, se

\footnotetext{
${ }^{44}$ Estudo realizado pela Oxfam Brasil, divulgado no final de 2016, com base no último Censo Agropecuário divulgado datado de 2006, toma-se ciência de que "Grandes propriedades somam apenas 0,91\% do total dos estabelecimentos rurais brasileiros, mas concentram $45 \%$ de toda a área rural do país. Por outro lado, os estabelecimentos com área inferior a dez hectares representam mais de $47 \%$ do total de estabelecimentos do país, mas ocupam menos de 2,3\% da área total". OXFAM Brasil. Terras da Desigualdade: terra, agricultura e desigualdades no Brasil Rural. $2016 . \quad$ Disponível em <https://www.oxfam.org.br/sites/default/files/arquivos/relatorio-terrenos_desigualdade-brasil.pdf> Acesso em: 25 nov.2018.

${ }^{45}$ Art. $5^{\circ}$, XXIII, da Constituição Federal: Todos são iguais perante a lei, sem distinção de qualquer natureza, garantindo-se aos brasileiros e aos estrangeiros residentes no País a inviolabilidade do direito à vida, à liberdade, à igualdade, à segurança e à propriedade, nos termos seguintes: XXIII - a propriedade atenderá a sua função social.

${ }^{46}$ O Decreto 9.311/18 dispõe sobre o processo de seleção, permanência e titulação das famílias beneficiárias do Programa Nacional de Reforma Agrária, um que vez que regulamenta, à luz da lei 13.465/17, a lei 13.001/14, que, por sua vez, dispõe sobre a liquidação de créditos concedidos aos assentados da reforma agrária, bem como a lei 8.629/93, que regulamenta os dispositivos
} 
inscreverão na tentativa de preencher os requisitos para concessão da parcela. $\mathrm{O}$ edital será elaborado com fundamento nas hipóteses em que são vedadas a concessão do lote e nos casos em que a concessão é prioritária (arts. $7^{\circ}$ e $9^{\circ}$, Decreto 9.311/18). Além disso, cria-se tabela de classificação das famílias a partir da maior pontuação alcançadas nos critérios estabelecidos pela lei. ${ }^{47}$ Sobre esse sistema, é preciso destacar o surgimento de uma condição de fragilidade para as famílias que ocupam a terra e que constroem o território a partir da relação com o meio ambiente físico e cultural. A lei estabelece como prioridade para concessão de lote o antigo proprietário desapropriado e, consecutivamente, os trabalhadores rurais arrendatários, posseiros, assalariados ou parceiros do imóvel desapropriado, reafirmando um cenário de conflito de terra. Nesse contexto, percebe-se um desvirtuamento da política de construção de assentamentos rurais pautados em uma lógica comunitária e de vizinhança, apontando para um simples loteamento.

Outro ponto relevante trata das formas de consolidação dos assentamentos e a consequente desvinculação do órgão fundiário. O assentamento será considerado consolidado em duas hipóteses, a primeira quando conclusos os investimentos ${ }^{48}$ e concedidos os créditos de instalação para pelo menos $50 \%$ dos beneficiários (art. 46, Decreto 9.311/18). A segunda trata da 'emancipação' pelo tempo: quinze anos após sua implantação, o assentamento será considerado consolidado, independentemente do cumprimento

constitucionais relativos à reforma agrária. Disponível em: https://www2.camara.leg.br/legin/fed/decret/2018/decreto-9311-15marco-2018-786320-publicacaooriginal-155039-pe.html Acesso em: 26 de nov.2018.

${ }^{47}$ Art. 12. Caberá ao Incra, respeitada a ordem de preferência estabelecida no art. $9^{\circ}$, classificar os candidatos a beneficiários do PNRA, segundo os seguintes critérios e respectiva pontuação:

I - unidade familiar mais numerosa, cujos membros se proponham a exercer a atividade agrícola na área a ser assentada, conforme o tamanho da família e sua força de trabalho - até o limite de dez pontos;

II - unidade familiar que resida há mais tempo no Município em que se localize o projeto de assentamento para o qual se destine a seleção ou nos Municípios limítrofes - até o limite de dez pontos;

III - unidade familiar chefiada por mulher - cinco pontos;

IV - unidade familiar ou indivíduo integrante de acampamento situado no Município em que se localize o projeto de assentamento da seleção ou nos Municípios limítrofes - até o limite de quinze pontos, graduados conforme a proximidade do imóvel;

$\mathrm{V}$ - unidade familiar que contenha filho com idade entre dezoito e vinte e nove anos e cujos pai ou mãe seja assentado residente no mesmo projeto de assentamento para o qual se destina a seleção - até o limite de dez pontos;

VI - unidade familiar de trabalhador rural que resida no imóvel destinado ao projeto de assentamento para o qual se destina a seleção na condição de agregados - até dez pontos;

VII - tempo comprovado de exercício de atividades agrárias pela unidade familiar - até dez pontos; e

VIII - unidade familiar em situação de vulnerabilidade social e econômica, até o limite de dez pontos, graduados conforme a faixa de renda.

$\S 1^{\circ}$ As unidades familiares que, em 22 de dezembro de 2016, por força de contrato de comodato ou em decorrência de situação equivalente, residam ou estejam ocupando o imóvel a ser destinado ao projeto de assentamento, respeitada a ordem de preferência do art. 19 da Lei n ${ }^{\circ} 8.629$, de 25 de fevereiro de 1993, terão prioridade na classificação de que trata este artigo.

$\S 2^{\circ}$ As pontuações previstas neste artigo são cumulativas e serão atribuídas conforme disciplinado pelo Incra.

$\S 3^{\circ}$ Considera-se a unidade familiar chefiada por mulher aquela em que, independentemente do estado civil, a mulher seja responsável pela maior parte do sustento material de seus dependentes.

$\S 4^{\circ} \mathrm{Na}$ hipótese de empate, terá preferência a unidade familiar candidata chefiada pela pessoa mais velha.

${ }^{48}$ O Decreto define no inciso I, do artigo 46, o que se entende por "conclusão de investimentos" como:

"I- conclusão de investimentos:

a) a execução dos serviços de medição e demarcação topográfica georreferenciada do perímetro e das parcelas do projeto de assentamento, conforme critérios estabelecidos pelo Incra; e

b) a viabilização de meios de acesso no assentamento que permitam o trânsito de pessoas e o escoamento da produção e a instalação de energia elétrica, de abastecimento de água e de moradia no assentamento." 
dos requisitos de concessão de créditos de instalação e conclusão dos investimentos (art. 47, Decreto 9.311/18).

Por fim, como outra face da mesma moeda, cabe atenção especial à política de titulação definitiva dos lotes, que tem como finalidade a privatização de terras públicas e, como consequência, a volta dessas terras para o mercado imobiliário abrindo espaço para uma reconcentração fundiária. ${ }^{49} \mathrm{O}$ Instituto Nacional de Colonização e Reforma Agrária (INCRA) adotou como prioridade orçamentária a titulação, isso fica evidente quando, “em 2017, foram emitidos 123 mil títulos, um recorde em relação aos governos anteriores, cuja média entre 2003 e 2016 girou em torno de 20 mil títulos/ano". 50

O não reconhecimento da importância da agricultura familiar no Brasil refletiu-se, ainda, em recente votação na ONU sobre o direito dos camponeses, onde o terceiro comitê da Assembleia Geral das Nações Unidas votou a favor da declaração, ${ }^{51}$ aprovada com 119 votos favoráveis, estando o Brasil entre os 49 países que se abstiveram, desde as primeiras rodadas, alegando a necessidade de novas negociações. ${ }^{52} \mathrm{~A}$ Declaração visa garantir a proteção dos direitos de todas as populações rurais, sejam elas camponesas, pescadores, artesanais, nômades ou agricultores, abarcando ainda comunidades indígenas e quilombolas, no caso do Brasil.

Outras iniciativas legislativas ainda merecem ser destacadas, ainda que não tenham sido aprovadas. Dentre elas, o Projeto de Lei (PL) 4576/2016, de autoria de Edinho Bez (PMDB/SC), que restringe a venda direta de produtos orgânicos por pequenos produtores rurais. Em um contexto campesino em que as políticas públicas de incentivo à agricultura familiar são escassas, o projeto tende a dificultar ainda mais tal atividade econômica. ${ }^{53}$ Além disso, há ainda o PL 827/2015, que pretende instituir a Lei de Proteção de Cultivares, ${ }^{54}$ em tramitação no Congresso Nacional. Esse projeto de lei pretende alterar a Lei $n^{\circ} 9.456$, de 25 de abril de 1997, que institui a Lei de Proteção de Cultivares, e também poderá dificultar a criação, produção, distribuição e armazenamento de sementes por parte de pequenos agricultores, especialmente conforme seus costumes tradicionais.

\footnotetext{
${ }^{49}$ SAUER, Sérgio e LEITE, Acácio Z. Medida Provisória 759: descaminhos da reforma agrária e legalização da grilagem de terras no Brasil. Retratos de assentamentos, vol. 20, p. 22.

${ }^{50}$ MALERBA, Julianna. Reconcentração Fundiária será o maior legado da contrarreforma agrária do governo Temer. Brasil em 5. 2018. Disponível em: <https://brasilem5.org/2018/03/20/reconcentracao-fundiaria-sera-o-maior-legado-dacontrarreforma-agraria-do-governo-temer/>. Acesso em: 21 de nov. 2018.

51 Disponível em: <http://www.mst.org.br/2018/11/24/onu-aprova-a-declaracao-sobre-direitos-dos-camponeses-ecamponesas.html>. Acesso em: 25 nov.2018.

52 Disponível em: <http://www.camara.gov.br/proposicoesWeb/fichadetramitacao?idProposicao=2078410>. Acesso em 25 nov.2018.

53 Disponível em: <https://exame.abril.com.br/brasil/camara-aprova-projeto-de-lei-que-restringe-venda-direta-de-organicos/>. Acesso em 25 nov.2018.

54 "Cultivar é o nome dado às espécies de plantas que tenham sido modificadas por alterações ou introduções feitas pelos homens, geralmente desenvolvidas no cruzamento entre espécies puras diferentes, e que são encontradas naturalmente no meio ambiente". PINHATA, Thais. Projeto de Lei quer proibir agricultores de livremente produzir, distribuir e armazenar sementes. Justificando. Disponível em: <http://www.justificando.com/2018/10/12/projeto-de-lei-quer-proibir-agricultores-de-livrementeproduzir-distribuir-e-armazenar-sementes/>. Acesso em: 25 nov.2018.
} 
Verifica-se, assim, que há um movimento de enfraquecimento das políticas de reforma agrária, que tem a Lei 13.465/2017 como um de seus importantes marcos, mas que se associa a outras tantas iniciativas normativas de enfraquecimento de garantia do direito à terra e ao meio ambiente equilibrado.

\section{UM CÓDIGO FLORESTAL PARA OS GRANDES PROPRIETÁRIOS}

O Código Florestal de 2012 (Lei 12.651/2012) é resultado de um processo legislativo controverso, bastante acompanhado pela sociedade, comunidade científica e imprensa, em que prevaleceu os interesses de determinado setor agrícola. De acordo com a argumentação prevalente no processo legislativo dessa norma, era preciso 'adequar' a norma ambiental à realidade brasileira, em que $90 \%$ dos proprietários rurais não cumpriam com a então vigente Lei 4.771/1965. ${ }^{55}$ Contrapunha-se, diretamente, a necessidade de adequação da norma à realidade social. Houve, assim, uma articulação política para alteração das normas em vigor, no sentido de abrandar as regras de proteção ambiental, especialmente as que incidem sobre a área rural, além de regularizar práticas que vinham sendo feitas ilegalmente.

Nesse sentido, o texto aprovado pode ser caracterizado, inicialmente, pela diminuição da proteção de áreas de preservação permanente (APP’s), ainda que possuíssem comprovada função ambiental, sendo muitos os casos que se poderiam mencionar para comprovar esse argumento, mas o que não será possível fazer nesse trabalho. Citam-se, como exemplos, os apicuns, o entorno de nascentes intermitentes, bem como o próprio modo de caracterização das matas ciliares que passam a ser consideradas a partir da borda da calha do leito regular, e não mais do leito de maior cheia. ${ }^{56}$ Em relação à diminuição da proteção, pode-se destacar, ainda, o estabelecimento de exceções ao regime geral de proteção das áreas de preservação permanente, como ocorre nos casos de matas ciliares no entorno de reservatórios artificiais de água que não decorram de barramento ou represamento de cursos d'água naturais, ${ }^{57}$ e acumulações naturais ou artificiais de água com superfície inferior a 1 (um) hectare, ${ }^{58}$ que deixam de serem consideradas como APP's.

O Código Florestal pode ser caracterizado, ainda, pela regularização de atividades que ocorriam em dissonância ao então Código Florestal (Lei 4.771/1965), diante da criação da área rural consolidada, ${ }^{59}$ bem como pela anistia de multas e crimes relativos a essa mesma lei revogada. Nesse sentido, os responsáveis pelas atividades que ocorriam ilegalmente tiveram os benefícios da anistia da obrigação de reparação dos danos ambientais, das multas e crimes decorrentes destas condutas ilegais. Esses proprietários foram agraciados, sem qualquer contraprestação, em relação aos que cumpriam com a então lei em vigor, a eles

\footnotetext{
55 Por todos, v. SALOMON, Marta. Reforma do Código beneficiaria 90\%. ESTADÃO. 12.05.2011. Disponível em: <http://www.estadao.com.br/noticias/geral,reforma-do-codigo-beneficiaria-90-imp-,718130>. Acesso em: 08 jul.2018.

${ }^{56}$ Art. $4^{\mathrm{o}}$, I e IV e art. $11 \mathrm{~A}, \S 1^{\mathrm{o}}$, Lei $12.651 / 2012$.

${ }^{57}$ Art. $4^{\mathrm{o}}, \S 1^{\mathrm{o}}$, Lei $12.651 / 2012$.

${ }^{58}$ Art. $4^{\mathrm{o}}, \S 4^{\mathrm{o}}$, Lei $12.651 / 2012$.

59 Pela definição legal, a área rural consolidada é "área de imóvel rural com ocupação antrópica preexistente a 22 de julho de 2008, com edificações, benfeitorias ou atividades agrossilvipastoris, admitida, neste último caso, a adoção do regime de pousio" (art. 3º, V, Lei 12.651/2012).
} 
sendo garantido, ainda hoje, um regime diferenciado (repita-se, um regime mais favorável em relação aos que estavam regulares) de utilização dos imóveis rurais. No entendimento de ABELHA, a criação das áreas rurais consolidadas teve como único objetivo "legalizar inúmeras situações de ilícitos ambientais de infratores que desrespeitaram a legislação ambiental por terem destruído áreas de preservação permanente e de reserva ambiental". 60

Neste aspecto é importante lembrar que o regime jurídico das áreas rurais consolidadas permite a continuidade das atividades agrosilvipastoris, de ecoturismo e de turismo rural em áreas de preservação permanente, estabelecendo-se poucas regras de recuperação ambiental. ${ }^{61}$ Dentre as regras destinadas a recomposição florestal, destacam-se às relativas às matas ciliares que utilizam como critério para determinar a extensão da APP o tamanho da propriedade - e não mais a largura do curso d'água. ${ }^{62}$

Por fim, como um último pilar do então Código Florestal, tem-se a instituição de um mercado de pagamento por serviços ambientais no Brasil, que igualmente trouxe o argumento da necessidade de concessão de incentivos financeiros aos proprietários, considerados fornecedores de serviços ambientais e agentes da preservação ambiental como um todo, mas que beneficia a todos, indistintamente, inclusive os que descumpriram a legislação. A lógica por traz da implementação dos pagamentos por serviços ambientais (PSA) descansa no pensamento da necessidade em se compensar os indivíduos promotores da preservação ambiental. Ou seja, a lógica que permeia os pagamentos por serviços ambientais no Código Florestal é a de promover um retorno financeiro aos indivíduos que preservam a vegetação nativa em suas propriedades privadas, independente se tiveram seus passivos, infrações e crimes ambientais anistiadas ou não.

Embora, durante todo o processo legislativo, existisse uma constante argumentação da necessidade de abrandar as normas que incidiam sobre pequenas propriedades ou agricultores familiares, pesquisas demonstram que os maiores beneficiários da alteração legislativa foram os grandes proprietários. Os números de áreas que deixaram de ser protegidas são bastantes expressivos. Segundo IMAFLORA, as anistias da reduziram o passivo de APP’s e RL’s em 41 milhões de hectares de vegetação nativa que deveriam, à luz da legislação anterior, ser restaurados. Os grandes imóveis, embora representem apenas 6\% do total de imóveis rurais no país, possuem 59\% das áreas com déficit de RL ou APP. Os pequenos imóveis (menores do que 4 módulos fiscais) representam 82\% do número de imóveis e possuem apenas $6 \%$ das áreas com déficit. ${ }^{63}$

\footnotetext{
${ }^{60}$ RODRIGUES, Marcelo Abelha. Áreas consolidadas no Código Florestal (Lei 12.651/2012): uma vergonha sem precedentes no Direito Ambiental brasileiro. In Revista de Direito Ambiental. N, 69: 345-356. São Paulo: Revista dos Tribunais, 2013. Pg. 347.

${ }^{61}$ Arts. 61A-63, Lei 12.651/2012.

${ }^{62}$ Art. $61^{\mathrm{a}}$, § $1^{\circ}-4^{\circ}$, Lei $12.651 / 2012$.

${ }^{63}$ GUIDOTTI, Vinicius et al. Números detalhados do Novo Código Florestal e suas implicações para os PRAs. Sustentabilidade em Debate, n. 5 , 2017. Disponível em:

<http://www.imaflora.org/downloads/biblioteca/5925cada05b49_SUSTemDEB_low_web_links.pdf>. Acesso em: 28 nov.2018.
} 
Além disso, deve-se notar que a lógica prevalente no Código Florestal, inclusive seu principal instrumento que é o Cadastro Ambiental Rural, é a da propriedade individual - e não distingue os diversos usos coletivos que são feitos das posses e propriedades no Brasil, como os relacionados a terras indígenas, quilombolas e de comunidades tradicionais, assentamentos rurais, dentre outros.

\section{CÓDIGO FLORESTAL DE 2012 E SUAS REGRAS ESPECÍFICAS SOBRE AGRICULTURA FAMILIAR E ASSENTAMENTOS RURAIS}

Não obstante o Código Florestal voltar-se aos grandes proprietários ou empresários do campo, e à lógica da propriedade individual, há algumas normas específicas relacionadas a agricultores familiares e assentamentos rurais. Nota-se que os assentamentos e projetos de reforma agrária são considerados pequenas propriedades ou posses rurais familiares, e, por isso, a eles são aplicáveis todas as normas a respeito destas. ${ }^{64}$

Há regras específicas sobre intervenção em APP's, uma vez que é considerada, como de interesse social, a exploração agroflorestal sustentável praticada na pequena propriedade ou posse rural familiar ou por povos e comunidades tradicionais, desde que não descaracterize a cobertura vegetal existente e não prejudique a função ambiental da área, ${ }^{65}$ e, ainda, é caracterizada como atividade eventual ou de baixo impacto ambiental, a construção de moradia de agricultores familiares, remanescentes de comunidades quilombolas e outras populações extrativistas e tradicionais em áreas rurais, onde o abastecimento de água se dê pelo esforço próprio dos moradores. ${ }^{66}$

Nas áreas de preservação permanente de assentamentos rurais é admitido o plantio de culturas temporárias e sazonais de vazante de ciclo curto na faixa de terra que fica exposta no período de vazante dos rios ou lagos, desde que não implique supressão de novas áreas de vegetação nativa, seja conservada a qualidade da água e do solo e seja protegida a fauna silvestre. ${ }^{67}$

A Lei estabelece, ainda, regras e procedimentos simplificados para os assentamentos, como para elaboração, análise e aprovação de planos de manejo de reserva legal, ${ }^{68}$ de florestas nativas e formações sucessoras, ${ }^{69}$ bem como para licenciamento ambiental de Plano de Manejo Florestal Sustentável (PMFS) comercial, ao qual ainda incidem normas especiais. ${ }^{70}$

\footnotetext{
${ }^{64}$ Art. $3^{\circ}$, V, Lei $12.651 / 2012$.

${ }^{65}$ Art. $3^{\circ}$, IX, Lei $12.651 / 2012$.

${ }^{66}$ Art. $3^{\circ}$, X, Lei 12.651/2012. De acordo com a Lei, “A intervenção e a supressão de vegetação em Áreas de Preservação Permanente e de Reserva Legal para as atividades eventuais ou de baixo impacto ambiental, previstas no inciso $\mathrm{X}$ do art. $3^{\circ}$, excetuadas as alíneas $b$ e $g$, quando desenvolvidas nos imóveis a que se refere o inciso $\mathrm{V}$ do art. $3^{\circ}$, dependerão de simples declaração ao órgão ambiental competente, desde que esteja o imóvel devidamente inscrito no CAR" (art. 52).

${ }^{67}$ Art. $4^{\circ}, \S 5^{\circ}$, Lei $12.651 / 2012$.

${ }^{68}$ Art. $17, \S 2^{\circ}$, e 57 , Lei $12.651 / 2012$.

${ }^{69}$ Art. $31, \S 6^{\circ}$, Lei $12.651 / 2012$.

${ }^{70}$ Art. 56, Lei $12.651 / 2012$.
} 
O Código Florestal de 2012 traz um capítulo específico destinado à agricultura familiar, com regras sobre reserva legal, Cadastro Ambiental Rural (CAR), licenciamentos simplificados e programa de apoio técnico. $^{71}$

Sobre a reserva legal de assentamentos, a Lei determina que poderão ser computados os plantios de árvores frutíferas, ornamentais ou industriais, compostos por espécies exóticas, cultivadas em sistema intercalar ou em consórcio com espécies nativas da região em sistemas agroflorestais. ${ }^{72}$

Em relação ao apoio técnico e de incentivos financeiros aos assentamentos, e demais atividades consideradas como agricultura familiar, o Código prevê no caso de recomposição da vegetação da Reserva Legal $^{73}$ e de outras atividades de preservação, de modo mais geral, de acordo com o artigo 58 do diploma legal. Além disso, estabelece-se prioridade, aos agricultores familiares, para pagamento ou incentivo a serviços ambientais previstos no artigo 41, I, do Código. Além disso, há regra específica para recomposição de áreas consolidadas em Áreas de Preservação Permanente ao longo ou no entorno de cursos d'água, lagos e lagoas naturais em assentamentos do Programa de Reforma Agrária, determinando-se que deverá observar os limites de cada área demarcada individualmente, objeto de contrato de concessão de uso, até a titulação por parte do Instituto Nacional de Colonização e Reforma Agrária (INCRA). ${ }^{74}$

Nesse sentido, embora o novo Código Florestal represente interesses desvinculados dos agricultores familiares, algumas normas os beneficiam e instituem um regime jurídico específico que busca atender suas peculiaridades.

\subsection{O julgamento da constitucionalidade do Código Florestal de 2012 pelo Supremo Tribunal Federal}

A Lei 12.651/2012 foi objeto de cinco ações propostas no Supremo Tribunal Federal (STF), sendo três de autoria do Ministério Público Federal, uma do Partido Socialismo e Liberdade (PSOL) e outra do Partido Progressista (PP) julgadas em fevereiro de 2018. ${ }^{75}$ Em sua maioria, os artigos questionados foram declarados constitucionais, com exceção de alguns poucos aos quais se deu interpretação conforme a Constituição Federal76 ou declarou-se a inconstitucionalidade77.

Para este

\footnotetext{
${ }^{71}$ Art. 52 e seguintes, Lei $12.651 / 2012$.

${ }^{72}$ Art. 54, Lei 12.651/2012.

${ }^{73}$ Art. 54, parágrafo único, Lei 12.651/2012.

${ }^{74}$ Art. 61C, Lei 12.651/2012.

${ }^{75} \mathrm{O}$ acórdão ainda não foi publicado. As ações em questão, que tiveram julgamento conjunto, são: Ação Declaratória de Constitucionalidade (ADC) 42 e Ações Diretas de Inconstitucionalidade (ADIs) 4901, 4902, 4903 e 4937 ”. Disponível em: <http://www.stf.jus.br/portal/cms/verNoticiaDetalhe.asp?idConteudo=370937 >. Acesso em: 21 nov.2018.

${ }^{76}$ O STF concedeu interpretação conforme a Constituição para exigir a comprovação de inexistência de alternativa técnica ou locacional aos casos de intervenção em APP por utilidade pública ou interesse social (art. $3^{\circ}$, VIII e IX), bem como para considerar como APP o entorno de nascentes e olhos d’àgua intermitentes (art. $3^{\circ}$, XVII e art. $4^{\circ}$, IV). Além disso, em relação a compensação de área de reserva legal desmatada, condicionou-se à existência de identidade ecológica com o espaço correspondente, localizado no mesmo bioma (art. $48, \S 2^{\circ}$ )
} 
artigo, importa destacar os dispositivos questionados que se referem especificamente à agricultura familiar, o que será feito a seguir.

Um dos objetos de questionamento sobre a constitucionalidade diz respeito à extensão do regime jurídico dispensado a pequena propriedade ou posse rural familiar as propriedades com até 4 (quatro) módulos fiscais, bem como às terras indígenas demarcadas ou tradicionais tituladas que façam uso coletivo. Questiona-se, assim, o parágrafo único do artigo $3^{\circ}$ da Lei 12.651/12 que determina: "Para os fins desta Lei, estende-se o tratamento dispensado aos imóveis a que se refere o inciso $\mathrm{V}$ deste artigo às propriedades e posses rurais com até 4 (quatro) módulos fiscais que desenvolvam atividades agrossilvipastoris, bem como às terras indígenas demarcadas e às demais áreas tituladas de povos e comunidades tradicionais que façam uso coletivo do seu território".

Existe um tratamento jurídico diferenciado para agricultores familiares e pequenos produtores, entendendo-se que os primeiros possuem as particularidades oriundas de um sistema de produção que usa, de modo predominante, mão de obra da oriunda da sua família. Neste sentido, a Lei 11.326/2016, que aponta as diretrizes para a formulação da Política Nacional da Agricultura Familiar e Empreendimentos Familiares Rurais, estabelece que seus destinatários devem utilizar-se predominantemente mão de obra da própria família nas atividades econômicas do seu estabelecimento ou empreendimento, bem como tenha percentual mínimo da renda familiar originada de atividades econômicas do seu estabelecimento ou empreendimento.

O Código Florestal ignora essas diferenças ao conferir tratamento igual para realidades completamente diferentes, permitindo, por exemplo, a intervenção em área de preservação permanente e reserva legal por qualquer proprietário ou possuidor rural de até 4 módulos fiscais, independentemente do uso que se faça da terra ou de ser um agricultor familiar (arts. 52 e 57, Lei 12.651/2012). A Lei aprovada não leva em consideração as distintas formas de uso da terra, em especial, os usos coletivos e compartilhados dos territórios e seus recursos naturais. No julgamento, o Supremo declarou essa equiparação compatível com a Constituição Federal.

Além disso, o Código Florestal trazia a necessidade de demarcação de terras indígenas e titulação de terras tradicionais para alcançar esse regime diferenciado, sem considerar que a titulação é mero ato formal de reconhecimento de uma relação originária e tradicional com o território, o que se torna mais grave quando somado ao cenário de omissão do Estado quanto à demarcação de terras. Sobre isso, a maioria dos Ministros do STF entendeu inconstitucional as expressões “demarcadas" e "tituladas".

Outro ponto discutido pelo STF foi a admissão de plantio de culturas temporárias e sazonais de vazante de ciclo curto em área de preservação permanente em pequenas propriedades $\left(\operatorname{art} .4^{\circ}, \S 5^{\circ}\right.$, Lei

\footnotetext{
${ }^{77}$ O STF declarou inconstitucionais a possibilidade de intervenção em áreas de preservação permanente para "gestão de resíduos sólidos" e "competições esportivas estaduais, nacionais ou internações" (art. 3, VIII, 'b') e a exigência de demarcação de Terras Indígenas e titulação de terras de comunidades tradicionais para tutela especial ( $\operatorname{art.} 3^{\circ}$, parágrafo único).
} 
12.651/12). Argumentou-se que o dispositivo violava o princípio da vedação ao retrocesso socioambiental, exceto em relação a comunidades tradicionais, em que deveria ocorrer o reconhecimento cultural material e imaterial dessas comunidades, ${ }^{78}$ motivo pelo qual pleiteava-se a interpretação conforme a Constituição Federal. Por unanimidade, os Ministros declararam constitucional a previsão do Código Florestal.

Por fim, destaca-se a manutenção do art. $12, \S^{\circ}$, que permite a redução, para fins de recomposição, do percentual mínimo de reserva legal situada em área de florestal na Amazônia Legal de 80\% para 50\%, nos municípios que tiverem mais de 50\% da sua área total ocupadas com Terras Indígenas e/ou unidades de conservação. A questão suscitada relacionava-se a distintas finalidades da manutenção da Reserva Legal, da demarcação das Terras Indígenas e da instituição de Unidades de Conservação, tornando-se sem sentido, portanto, a substituição entre elas.

\section{CADASTRO AMBIENTAL RURAL (CAR) E ASSENTAMENTOS RURAIS}

O CAR é um registro público nacional, obrigatório para todos os possuidores ou proprietários rurais, ${ }^{79}$ sendo um dos instrumentos centrais para cumprimento e verificação das obrigações que decorrem do Código Florestal. Atualmente, o prazo para inscrição dos imóveis rurais no CAR é 31 de dezembro de 2018. ${ }^{80} 81$ O objetivo do Cadastro Ambiental Rural é reunir as principais informações ambientais sobre imóveis rurais no Brasil, constituindo uma base de dados destinada à fiscalização e formulação de políticas públicas.

Uma das principais características do CAR é o seu caráter auto declaratório, ou seja, o posseiro, proprietário rural ou órgão responsável pela inclusão das informações no CAR, o faz de maneira autônoma, com auxílio de técnico especializado, ou não, por meio de um sistema eletrônico denominado SISCAR, e essa declaração já produz efeitos jurídicos.

\footnotetext{
${ }^{78}$ BITTENCOURT, Naiara. Placar do julgamento do código florestal no STF - Lei 12.651/12. Terra de Direitos. 2018. Disponível em: <https://terradedireitos.org.br/noticias/noticias/placar-do-julgamento-do-codigo-florestal-no-stf-lei126512012/22752>. Acesso em: 21 nov.2018.

${ }^{79}$ Art. 29, Lei $12.651 / 2012$.

${ }^{80}$ Art. $29, \S 3^{\circ}$, Lei $12.651 / 2012$.

${ }^{81}$ Em 2018, cinco anos passados da promulgação da lei, ainda encontramos imóveis não cadastrados e tendo o governo federal estendido o prazo para cadastramento por mais um ano, até 31 de dezembro de 2018 . Disponível em <https://www.noticiasagricolas.com.br/noticias/agronegocio/215012-prorrogacao-do-prazo-do-car-ate-31-de-dezembro-vaibeneficiar-18-dos-produtores-de-ms-que-ainda-nao.html\#.W0Iul9hKgdU>. Acesso em: 08 jul.2018.

Segundo informações do Serviço Florestal Brasileiro, responsável pela divulgação de dados parciais quanto aos imóveis já cadastrados, até 31 de outubro de 2018 havia 5.414.621 imóveis inscritos no CAR. Importante destacar que a soma da área declarada pelos proprietários representa um percentual maior do que a área passível de cadastramento, o que significa que a averbação do perímetro não é compatível com a realidade da malha fundiária rural. As informações disponíveis no Boletim não possibilitam uma analise diferenciada da inscrição de pequena propriedade destinada à agricultura familiar dos demais imóveis . Disponível em: <http://www.florestal.gov.br/documentos/car/boletim-do-car/3936-tabela-calculos-boletim-sicar-outubro2018-revrej/file>. Acesso em: 22 nov.2018.
} 
Enquanto não houver manifestação do órgão competente acerca das informações declaradas no CAR, a inscrição do imóvel estará efetivada para todos os fins previstos no Código Florestal. ${ }^{82}$ Isso significa que os benefícios trazidos pelo Código Florestal aos proprietários ou posseiros de imóveis dependem tão somente das informações por eles declaradas no cadastro. Os principais efeitos da inscrição do imóvel no CAR são a obtenção e acesso ao crédito rural, ${ }^{83}$ aos Programas de Recuperação Ambiental (PRA) ${ }^{84}$ e a possibilidade de geração de Cotas de Reserva Ambiental (CRA). ${ }^{85}$

Nesse sentido, torna-se primordial que os órgãos ambientais atuem no sentido da fiscalização sobre a veracidade das informações e cumprimento das obrigações que decorrem do Cadastro. Atualmente, tem-se visto que a fiscalização está ocorrendo de modo remoto e que, embora exista uma previsão da possibilidade de o órgão ambiental competente realizar vistorias de campo para fiscalizar as informações declaradas no cadastro, ${ }^{86}$ isso ainda não vem acontecendo.

Nota-se, ainda, a desvinculação do CAR da questão fundiária, prevendo-se, expressamente, que o cadastramento não será considerado título para fins de reconhecimento do direito de propriedade ou posse. ${ }^{87}$ E, nesse sentido, não há qualquer disposição sobre análise da documentação sobre posse e propriedade, havendo, ainda, a possibilidade de 'responsável direto', que não seja o proprietário ou possuidor, estar incluído no cadastro. ${ }^{88}$ Ocorre, contudo, essa escolha legislativa torna-se ambígua já que se, por um lado, viabilizou a existência de um cadastro com amplitude nacional, em um país que historicamente possui disputas fundiárias, inclusive em relação aos registros das terras, por outro lado, trouxe o problema da veracidade das informações que vem sendo incluídas no CAR. Os dados divulgados, que refletem as disputas de terras em curso no Brasil, indicam um número maior de área cadastrada que a existente, ${ }^{89}$ evidenciando-se sobreposições, ${ }^{90}$ inclusive em relação à terras públicas, unidades de conservação, terras indígenas demarcadas, territórios de comunidades tradicionais, dentre outros. ${ }^{91}$ Além disso, tem-se visto que o Cadastro pode vir a ser utilizado para fins fundiários, havendo inclusive manifestações nesse sentido. ${ }^{92}$

\footnotetext{
${ }^{82}$ Art. $7^{\mathrm{o}}, \S 2^{\circ}$, Decreto $7.830 / 2012$.

${ }^{83}$ Art. 78A, Lei $12.651 / 2012$.

${ }^{84}$ Art. 59, § $2^{\circ}$, Lei $12.651 / 2012$.

${ }^{85}$ Art. $44, \S 1^{\circ}$, Lei $12.651 / 2012$.

${ }^{86}$ Art. $7^{\circ}, \S 3^{\circ}$, Decreto $7.830 / 2012$.

${ }^{87}$ Art. $29, \S 2^{\circ}$, Lei $12.651 / 2012$.

${ }^{88}$ Art. $5^{\circ}$, Decreto 7.830/2012. V. MOREIRA, Elaine. O cadastro ambiental rural: a nova face da grilagem na Amazônia? Disponível em: <http://www.abrampa.org.br/site/?ct=noticia\&id=230>. Acesso em: 08 jul.2018.

${ }^{89}$ Esses dados são produzidos pelo Serviço Florestal Brasileiro. Disponível em: 〈http://www.florestal.gov.br/numeros-do-car〉. Acesso em: 08 jul.2018.

${ }^{90}$ Tem-se como exemplo o levantamento do Serviço Florestal Brasileiro divulgado pelo G1 que identificou 11.569 cadastros sobrepostos a terras indígenas, por exemplo. Disponível em: <http://g1.globo.com/natureza/noticia/cadastro-rural-tem-11-mildeclaracoes-de-propriedade-em-terras-indigenas.ghtml $>$. Acesso em: 08 jul.2018.

${ }^{91}$ BARROS, Ciro et al. As falhas e inconsistências do Cadastro Ambiental Rural. Pública. 1 ago.2016. Disponível em: <http://apublica.org/2016/08/as-falhas-e-inconsistencias-do-cadastro-ambiental-rural/>. Acesso em: 08 jul.2018.

92 OLIVEIRA, Ana Flávia de. Especialistas defendem integração de cadastros para a regularização de terras no Brasil. Disponível em: <http://mundogeo.com/blog/2017/06/05/especialistas-defendem-integracao-de-cadastros-para-a-regularizacao-deterras-no-brasil/>. Acesso em: 08 jul.2018.
} 
No caso de assentamentos rurais, há algumas peculiaridades quanto ao cadastramento de suas áreas. Este Cadastro é realizado pelo INCRA, ${ }^{93}$ por meio, inicialmente, de um procedimento simplificado, que dispensa a inclusão de determinadas informações, exigíveis aos demais. Para o cadastro de assentamentos, o Código Florestal exige apenas a apresentação de determinados documentos ${ }^{94}$ e de croqui indicando o perímetro do imóvel, as áreas de preservação permanente e os remanescentes que formam a reserva legal. ${ }^{95}$

De acordo com o procedimento atualmente em vigor, o INCRA faz a inscrição dos assentamentos rurais, mediante o registro do seu perímetro, com inclusão, por meio de planilha digital, da relação de beneficiários do assentamento de reforma agrária. ${ }^{96} \mathrm{Em}$ um segundo momento, os assentados devem efetuar seus cadastros individualizados, com apoio do INCRA, prevendo-se a possiblidade de serem obtidas as informações ambientais dos lotes por meio do cruzamento do seu polígono com o perímetro do assentamento. $^{97}$

Por fim, cabe destacar algumas regras previstas para os assentamentos rurais:

- para os assentamentos criados até 22 de julho de 2008, a Reserva Legal será constituída com a área ocupada com a vegetação nativa existente em 22 de julho de 2008;

- para os assentamentos criados após 22 de julho de 2008, a Reserva Legal será constituída pelos percentuais definidos no art.12 da Lei no 12.651, de 2012;

- para o cadastramento do perímetro do assentamento de reforma agrária ou para assentamentos onde não existe a individualização dos lotes, o cálculo da faixa marginal de recomposição de Áreas de Preservação Permanente ao longo ou no entorno de cursos d'água, lagos e lagoas naturais dar-se-á em função da fração ideal média do assentamento. ${ }^{98}$

As informações prestadas no Cadastro geram direitos e deveres, como a possibilidade de continuar com atividade agrossilvipastoris em determinadas áreas de preservação permanente, a obrigação de recuperação de APP’s e reservas legais, a impossibilidade de utilizar outras áreas. Assim, para além das regras específicas acima destacadas, importante ressaltar a necessária participação dos assentados na geração das informações a serem incluídas no Cadastro, bem como o amplo acesso aos estudos e dados produzidos no âmbito do INCRA. Além de não resguardar seus direitos, a falta de comunicação entre os assentados e o INCRA, no processo de cadastramento dos assentamentos, pode gerar problemas no que tange ao uso da

\footnotetext{
${ }^{93}$ A Lei expressamente indica que os órgãos competentes integrantes do SISNAMA, ou instituição por ele habilitada, devem realizar a captação das coordenadas geográficas necessárias para alimentar os cadastros de posses ou propriedades destinadas à agricultura familiar (art. 53, Lei 12.651/2012). E, ainda, o INCRA também deve assinar, juntamente com o assentado, o termo de compromisso oriundo da adesão ao programa de regularização ambiental (PRA) (art. 5º Decreto 8.235/2014), sendo responsável solidário pelo cumprimento das obrigações ambientais (arts. 56 e 57, Instrução Normativa 2/MMA/2014).

${ }^{94}$ Esses documentos são: identificação do proprietário ou possuidor rural; e comprovação da propriedade ou posse, previstos nos incisos I e II do $\S 1^{\circ}$ do art. 29.

${ }^{95}$ Art. 55, Lei 12.651/2012; art. $8^{\circ}$, Decreto 7.830/2012; e art. 14, Instrução Normativa 2/MMA/2014.

${ }^{96}$ Art. 53, Instrução Normativa 2/MMA/2014.

${ }^{97}$ Art. 55, Instrução Normativa 2/MMA/2014.

${ }^{98}$ Art. 56, Instrução Normativa 2/MMA/2014.
} 
propriedade rural e da própria vegetação nativa presente no interior dos lotes, uma vez que o cadastramento é feito por georeferenciamento, muitas vezes sem a devida inspeção técnica e participação dos assentados. ${ }^{99}$

\section{QUESTÕES RELATIVAS AS COTAS DE RESERVA AMBIENTAL (CRA'S) COM ORIGEM EM ASSENTAMENTOS RURAIS}

O Código Florestal traz, ainda, um capítulo sobre a possibilidade de instituição de um programa de apoio e incentivo à conservação do meio ambiente, que se traduz em pagamentos por serviços ambientais, compensação pelas medidas de conservação ambiental, necessárias ao cumprimento da Lei, bem como incentivos para comercialização, inovação e aceleração das ações de recuperação, conservação e uso sustentável das florestas e demais formas de vegetação nativa. ${ }^{100}$

Dentre essas normas, encontram-se as que tratam das cotas de reserva ambiental (CRA's), que representam uma remuneração aos proprietários rurais que possuem áreas com vegetação nativa excedentes em relação aos parâmetros determinados na legislação. Em outras palavras, o proprietário que possui área com vegetação nativa acima dos limites exigidos na legislação, poderá entrar em um mercado de negociação de títulos representativos desta mata. Essa previsão encontra-se no Capítulo X da Lei 12.561/2012, que trata sobre os pagamentos por serviços ambientais, uma novidade criada pelo novo Código Florestal.

As CRA's, assim, são títulos nominativos representativos de área com vegetação nativa, existente ou em processo de recuperação, que poderão ser utilizados para compensação de reserva legal de outrem ou, ainda, para negociação em mercados de cotas de carbono ou demais mercados de pagamentos por serviços ambientais.

A emissão da Cota ocorre por órgão competente do SISNAMA, em favor do proprietário rural que possui imóvel cadastrado no Cadastro Ambiental Rural. O título constitutivo da CRA, após emitido, deverá ser averbado na matrícula do imóvel no RGI competente. ${ }^{101}$ Cada unidade de Cota de Reserva Ambiental representa um hectare de área com vegetação nativa primária, ou secundária, em qualquer estágio de regeneração ou recomposição, bem como áreas de recomposição mediante reflorestamento com espécies nativas. ${ }^{102}$ Assim, o proprietário que tenha em seu imóvel rural tal excedente pode, por meio da geração de cotas, colocar à disposição no mercado os remanescentes florestais - ou áreas em processo de recuperação localizados no interior de sua propriedade e que representem excedentes de reserva legal.

\footnotetext{
${ }^{99}$ Sobre direito de participação e livre consentimento, mas especificamente de povos tradicionais, em relação ao CAR, v. SOUZA FILHO, C. F. M. e ROSITO, F. D (orgs). Estudos sobre o cadastro ambiental rural (CAR) e consulta prévia. $1^{\mathrm{a}}$ ed. Curitiba: Letra da Lei, 2016. p. 112.

${ }^{100}$ Art. 41, Lei 12.651/2012.

101 Art. 44, Lei 12.651/2012.

102 Art. 46, Lei 12.651/2012.
} 
E quem seriam os interessados em adquirir essas cotas? São os proprietários ou possuidores rurais que possuem áreas rurais consolidadas em reserva legal ${ }^{103}$ e que, atualmente, possuem três opções para sua regularização: (i) regeneração natural; (ii) recomposição florestal; ou (iii) compensação ambiental, ${ }^{104}$ o que pode ocorrer, dentre outras opções, por meio de aquisição das CRA's's. ${ }^{105}$

A emissão da CRA é realizada com base nas informações do imóvel rural cadastradas no CAR, o que nos devolve aos questionamentos anteriores sobre o caráter declaratório desse Cadastro e a necessidade de fiscalização por parte dos órgãos ambientais.

Como dito, pelo Código somente o proprietário do imóvel poderá solicitar a emissão das cotas, o que exclui os possuidores. ${ }^{106}$ Essa previsão levanta questionamentos quanto aos direitos territoriais e autonomias das comunidades tradicionais, assentamentos rurais e povos indígenas, já que, muitas vezes, seus territórios são propriedade da União. Em outras palavras, permite-se que a União (ou outro ente público detentor da propriedade) possa emitir cotas de territórios tradicionais e assentamentos rurais, por ser proprietário, desvinculando-se dos direitos dos reais ocupantes e detentores da terra? Entende-se que não. A emissão de cotas relacionadas aos assentamentos rurais - e outras áreas de usos coletivos - deve ser objeto de consenso entre a União, no caso de se tratar de terra pública federal, e os assentados, mediante processo que assegure o consentimento livre, prévio e informado, restando, inclusive, a necessidade de sua regulamentação, igualmente a ser definida de modo participativo.

Por fim, importa destacar que a responsabilidade pela conservação da vegetação nativa fica com o proprietário rural que gerou a cota (e não com o adquirente da mesma). ${ }^{107}$ Contudo, o verdadeiro encargo recairá sobre quem está na posse destes imóveis, sejam eles locatários, usufrutuários ou até possuidores, com título ou não. O Código Florestal de 2012 assim, além de anistiar os que não cumpriam com a legislação ambiental, acaba por transferir, muitas vezes, a responsabilidade pela manutenção da vegetação nativa ao elo mais fraco que são justamente os agentes de preservação ambiental. Nesse cenário, em relação aos assentamentos rurais, poderia restar, aos assentados, que possuem áreas protegidas além do que determina a legislação, ingressar nesse mercado de venda de cotas, arcando com a responsabilidade pela manutenção dessa vegetação nativa. Não se trata propriamente de uma opção, mas de uma falta de alternativa. Essa opção corresponderia a transferir, mais uma vez, o encargo da preservação ambiental, dessa vez dos que atuavam ilegalmente aos assentados.

\footnotetext{
${ }^{103}$ Ou seja, que não cumpriam com a legislação em 22 de julho de 2008 e precisam adotar medidas previstas no artigo 66 do Código para regularizar sua situação.

${ }^{104}$ A redação original do Código Florestal de 2012 trazia a permissão de compensação entre áreas do mesmo bioma - e não mais na mesma bacia hidrográfica, conforme o Código Florestal de 1965 (art. 66, § 5º Lei 12.651/2012). Contudo, em sede de julgamento das Ações de Inconstitucionalidade deste, ficou decidido que tal dispositivo deve ser interpretado conforme a Constituição de 1988 para permitir compensação apenas entre áreas com a mesma identidade ecológica.

105 Art. 66, Lei 12.651/2012.

${ }^{106}$ Art. 44, § $1^{\circ}$, Lei 12.651/2012. Assim, de acordo com o art. 44, no caso de assentamentos rurais, a União, por meio do INCRA, teria a atribuição de instituir a CRA para o excedente de reserva legal.

${ }^{107}$ Art. 49, Lei 12.651/2012.
} 
Nesse sentido, igualmente no que se refere aos pagamentos por serviços ambientais previstos no Código Florestal de 2012, em principal o dispositivo da Cota de Reserva Ambiental, privilegia-se o proprietário que não cumpria com a legislação e possuía um passivo ambiental, em detrimento da proteção e tutela do meio ambiente.

\section{CONCLUSÃO}

Esse trabalho objetivou apresentar as regras do Código Florestal de 2012 - e suas normas complementares - aplicáveis aos assentamentos rurais, como forma de visibilizar as discussões sobre direitos e garantias dos assentados, nas questões que envolvem a aplicação da Lei, especialmente os referentes à inscrição de suas terras no Cadastro Ambiental Rural e possíveis questões relacionadas à geração de Cotas de Reserva Ambiental, tendo em vista que esse mercado ainda não está funcionando plenamente.

Uma vez considerados como pequenas propriedades ou posses rurais familiares, os assentamentos e projetos de reforma agrária atraíram a aplicação de normas de proteção de florestas a eles direcionadas, além de outras expressamente previstas aos assentamentos, muitas referentes ao procedimento relacionado ao CAR. Nesse sentido, embora a aprovação do novo Código Florestal represente interesses desvinculados dos agricultores familiares, em que preponderaram os dos grandes proprietários rurais, algumas normas acabam os beneficiando e instituindo um regime jurídico mais específico que atenda às suas peculiaridades.

Foram previstas regras para os assentamentos rurais, sendo a maioria direcionada à simplificação dos procedimentos, pensando-se na viabilidade de se produzir o cadastramento de todos os assentamentos no Brasil. No entanto, não houve nenhuma previsão sobre a necessária participação dos assentados na geração das informações a serem incluídas no Cadastro, bem como o amplo acesso aos estudos e dados produzidos no âmbito do INCRA. Os direitos de ampla participação e informação devem ser assegurados aos assentados, em atendimento às normas constitucionais, e, inclusive, pelas consequências geradas aos possuidores, que são responsáveis pela manutenção e eventual recuperação de áreas de preservação permanente e reserva legal.

Igualmente no que se refere aos pagamentos por serviços ambientais não há sequer menção à geração de cotas originadas de excedentes de vegetação nativa em territórios de comunidades tradicionais, povos indígenas ou, ainda, de assentamentos rurais. Muito menos um disciplinamento específico, que seria exigível diante das inúmeras peculiaridades dessas áreas. Não há similaridades entre tais áreas e propriedades individuais, sejam elas públicas ou privadas. E, ainda que, muitas delas, sejam constituídas em terras públicas, os usos coletivos nelas realizados impõem tratamento diferenciado, o que não foi previsto no Código Florestal de 2012. 
A inexistência de um tratamento específico traduz-se em uma série de questionamentos como: em que casos poderão ser emitidas cotas em assentamentos rurais, como será a forma de participação dos assentados na decisão de emissão das cotas, de que modo ocorrerá a remuneração aos assentados pelos valores gerados pelas cotas, dentre outras. Nesse sentido, entende-se que a emissão de cotas relacionadas aos assentamentos rurais - e outras áreas de usos coletivos - deve ser amadurecida, largamente discutida entre os envolvidos e, ainda, regulamentada com regras específicas, a serem definidas de modo participativo.

Objetivou-se, assim, visibilizar o debate sobre os direitos dos agricultores e assentados e discutir o processo político que os tem preterido em detrimento de outros interesses, partindo-se, de um lado, da extrema importância da agricultura familiar, com a necessária discussão sobre políticas públicas que a viabilizem e desenvolvam, e, de outro, o acirramento de uma agenda política de benefício ao agronegócio e agricultura extensiva.

\section{REFERÊNCIAS}

BENJAMIN, Antônio Herman de Vasconcelos e. A proteção das Florestas Brasileiras: ascensão e queda do Código Florestal. In Revista de Direito Ambiental, v. 5, n. 18, p. 21-37, abr./jun. 2000. Disponível em: <http://bdjur.stj.jus.br//dspace/handle/2011/8962>. Acesso em: 08 jul. 2018.

BITTENCOURT, Naiara. Placar do julgamento do código florestal no STF - Lei 12.651/12. Terra de Direitos. 2018. Disponível em: https://terradedireitos.org.br/noticias/noticias/placar-do-julgamento-docodigo-florestal-no-stf-lei-126512012/22752 Acesso em: 21 nov. 2018.

BRASIL. Decreto $\mathbf{n}^{\mathbf{0}}$ 9.311, de 15 de março de 2018. Disponível em: https://www2.camara.leg.br/legin/fed/decret/2018/decreto-9311-15-marco-2018-786320-publicacaooriginal155039-pe.html Acesso em: 26 nov. 2018.

BRASIL. Lei Federal $\mathbf{n}^{\mathbf{0}}$ 11.326, de 24 de julho de 2016. Disponível em: http://www.planalto.gov.br/ccivil_03/_Ato2004-2006/2006/Lei/L11326.htm\#art3 Acesso em: 21 nov. 2018.

BRASIL. Lei Federal $\mathbf{n}^{\mathbf{0}} \mathbf{1 2 . 6 5 1}$, de 25 de maio de 2012. Disponível em: http://www.planalto.gov.br/ccivil_03/_Ato2011-2014/2012/Lei/L12651.htm Acesso em: 21 nov. 2018.

BRASIL. Lei Federal $\mathbf{n}^{\mathbf{0}} \mathbf{1 3 . 4 6 5}$, de 11 de julho de 2017. Disponível em: http://www.planalto.gov.br/ccivil_03/_ato2015-2018/2017/lei/113465.htm Acesso em: 26 nov. 2018.

BRASIL. Serviço Florestal Brasileiro. Cadastro Ambiental Rural: Boletim Informativo. 2018. Disponível em: http://www.florestal.gov.br/documentos/car/boletim-do-car/3936-tabela-calculos-boletimsicar-outubro2018-rev-rej/file Acesso em: 22 nov.2018.

DERANI, Cristiane. A propriedade na Constituição de 1988 e o conteúdo da "função social". In Revista de Direito Ambiental, v. 27, p. 58-69, 2002.

FIGUEREDO, Guilherme José Purvin de. A propriedade no Direito Ambiental. Rio de Janeiro: Esplanada, 2004. 
GUIDOTTI, Vinicius et al. Números detalhados do Novo Código Florestal e suas implicações para os PRAs.

Sustentabilidade em Debate, $\quad$ n. 4 5, $2017 . \quad$ Disponível em: <http://www.imaflora.org/downloads/biblioteca/5925cada05b49_SUSTemDEB_low_web_links.pdf>.

Acesso em: 28 nov.2018.

GUIMARÃES, Virgínia Totti. A (in)constitucionalidade do Novo Código Florestal no STF e o voto de Luiz Fux. Justificando. : Disponível em: <http://www.justificando.com/2017/12/05/inconstitucionalidadedo-novo-codigo-florestal-no-stf-e-o-voto-de-luiz-fux/> Acesso em: 28 nov. 2018

LOPES, Juliana Chermont Pessoa. Os pagamentos por serviços ambientais (PSA) e a descaracterização dos espaços especialmente protegidos. In Série Prêmio José Bonifácio de Andrada e Silva, Vol. 4. Ana Maria de Oliveira Nusdeo (Org.). São Paulo : Disponível em: <http://www.planetaverde.org/arquivos/biblioteca/arquivo_20180807153715_941.pdf>. Acesso em: 28 nov. 2018

MALERBA, Julianna. Reconcentração Fundiária será o maior legado da contrarreforma agrária do governo Temer. Brasil em 5. 2018. Disponível em: <https://brasilem5.org/2018/03/20/reconcentracaofundiaria-sera-o-maior-legado-da-contrarreforma-agraria-do-governo-temer/>. Acesso em: 21 nov. 2018.

MILARÉ, Edis. Direito do Ambiente. $9^{a}$ ed., revista, atual. e ampliada. São Paulo: Revista dos Tribunais, 2014.

MIRANDA, Ana Caroline Pires. Construção de dispositivos legais e agentes em disputa: o debate em torno do novo Código Florestal Brasileiro. Tese (Doutorado) - Universidade Federal do Maranhão, Programa de Pós-Graduação em Ciências Sociais, 2016.

MOREIRA, Elaine. $\mathbf{O}$ cadastro ambiental rural: a nova face da grilagem na Amazônia? Disponível em: <http://www.abrampa.org.br/site/?ct=noticia\&id=230>. Acesso em: 08 jul. 2018.

NETO, Salvador Xavier Júnior; et al. Diagnóstico do uso de agrotóxico na agricultura familiar na região de serra talhada-pe. XIII Jornada de ensino, pesquisa e extensão - Jepex 2013 - UFRPE: recife, 09 a 13 de dezembro. Disponível em: < http://www.eventosufrpe.com.br/2013/cd/resumos/r0202-1.pdf> Acesso em: 25 nov. 2018.

OLIVEIRA, Ana Flávia de. Especialistas defendem integração de cadastros para a regularização de terras no Brasil. Disponível em: <http://mundogeo.com/blog/2017/06/05/especialistas-defendemintegracao-de-cadastros-para-a-regularizacao-de-terras-no-brasil/>. Acesso em: 08 jul. 2018.

OXAM BRASIL. Terrenos da Desigualdade: Terra, agricultura e desigualdades no Brasil rural. 2016. Disponível em: <https://www.oxfam.org.br/sites/default/files/arquivos/relatorio-terrenos_desigualdadebrasil.pdf > Acesso em: 28 nov. 2018.

PINTO, Paula Máximo de Barros. Os direitos originários dos povos indígenas e as implicações da inscrição de suas terras no cadastro ambiental rural (CAR). In Série Prêmio José Bonifácio de Andrada e Silva, Vol. 4. Ana Maria de Oliveira Nusdeo (Org.). São Paulo : Disponível em: < http://www.planetaverde.org/arquivos/biblioteca/arquivo_20180807153715_941.pdf>. Acesso em: 28 nov. 2018 
RODRIGUES, Marcelo Abelha. Áreas consolidadas no Código Florestal (Lei 12.651/2012): uma vergonha sem precedentes no Direito Ambiental brasileiro. In Revista de Direito Ambiental. N, 69: 345-356. São Paulo: Revista dos Tribunais, 2013.

SALOMON, Marta. Reforma do Código beneficiaria 90\%. ESTADÃO. Disponível em: <http://www.estadao.com.br/noticias/geral,reforma-do-codigo-beneficiaria-90-imp-,718130>. Acesso em: 28 nov. 2018.

SAUER, Sérgio e LEITE, Acácio Z. Medida Provisória 759: descaminhos da reforma agrária e legalização da grilagem de terras no Brasil. Retratos de assentamentos, vol. 20, p. 14-40, 2017.

SILVA, José Antônio Aleixo da et al. O Código Florestal e a Ciência: contribuições para o diálogo. São Paulo: Sociedade Brasileira para o Progresso da Ciência, SBPC; Academia Brasileira de Ciências, ABC. 2011.

SOUZA FILHO, C. F. M. e ROSITO, F. D (orgs). Estudos sobre o cadastro ambiental rural (CAR) e consulta prévia. $1^{\mathrm{a}}$ ed. Curitiba: Letra da Lei, 2016. p. 112.

SOUZA, Oswaldo Braga de. STF considera constitucional grande parte do novo Código Florestal 2012. Disponível em: <https://www.socioambiental.org/pt-br/noticias-socioambientais/stf-consideraconstitucional-grande-parte-do-novo-codigo-florestal> Acesso em: 28 nov. 2018. 